\title{
Low pretransplant IgA level is associated with early post-lung transplant seromucous infection
}

Sudish C. Murthy, MD, PhD, ${ }^{\mathrm{a}}$ Robin K. Avery, MD, ${ }^{\mathrm{b}}$ Marie Budev, DO, MPH, ${ }^{\mathrm{c}}$ Sandeep Gupta, MD, ${ }^{\mathrm{a}}$ Gösta B. Pettersson, MD, PhD, ${ }^{a}$ Edward R. Nowicki, MD, MS, ${ }^{a}$ Atul Mehta, MD, Jeffrey T. Chapman, MD, ${ }^{c}$ Jeevanantham Rajeswaran, $\mathrm{PhD},{ }^{\mathrm{d}}$ and Eugene H. Blackstone, $\mathrm{MD}^{\mathrm{a}, \mathrm{d}}$

\section{ABSTRACT}

Objectives: Infection is an important cause of morbidity and mortality after lung transplantation. Immunoglobulins are part of both seromucous (IgA) and serum $(\mathrm{IgG})$ infection defense mechanisms. We therefore hypothesized that lower pretransplant IgA levels would be associated with more early post-lung transplant seromucous infections and greater mortality independent of IgG.

Methods: From January 2000 to July 2010, 538 patients undergoing primary lung transplantation had pretransplant $\operatorname{IgA}(\mathrm{n}=429)$ and $\operatorname{IgG}(\mathrm{n}=488)$ measured as a clinical routine. Median IgA was $200 \mathrm{mg} \cdot \mathrm{dL}^{-1}\left(2 \%<70 \mathrm{mg} \cdot \mathrm{dL}^{-1}\right.$, lower limit of normal); median $\mathrm{IgG}$ was $970 \mathrm{mg} \cdot \mathrm{dL}^{-1}\left(5 \%<600 \mathrm{mg} \cdot \mathrm{dL}^{-1}\right)$. Intensive microbiology review was used to categorize infections and their causative organisms within the first posttransplant year.

Results: In total, 397 seromucous infections were observed in 247 patients, most bacterial. Although IgA and IgG were moderately correlated $(\mathrm{r}=0.5, P<.0001)$, low pretransplant IgA was a strong risk factor $(P=.01)$ for seromucous infections, but pretransplant $\operatorname{IgG}$ was not $(P \geq .6)$. As pretransplant IgA levels fell below $200 \mathrm{mg} \cdot \mathrm{dL}^{-1}$, the risk of these posttransplant infections rose nearly linearly. Lower pretransplant levels of IgA were associated with greater posttransplant mortality to end of follow-up $(P=.004)$, but pretransplant IgG was not $(P \geq .3)$.

Conclusions: Low levels of preoperative IgA, an important immunoglobulin involved in mucosal immunologic defense, but not IgG, are associated with seromucous infections in the year after lung transplantation and increased follow-up mortality. It would appear prudent to identify patients with relative IgA deficiency at listing and to increase vigilance of monitoring for, and prophylaxis against, seromucous infection in this high-risk population. ( $\mathrm{J}$ Thorac Cardiovasc Surg 2018;156:882-91)

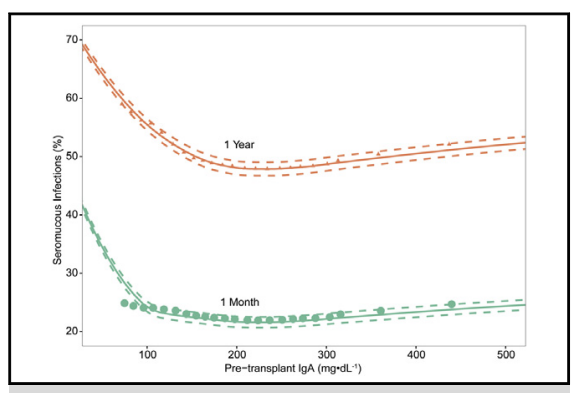

Pretransplant IgA and seromucous infections at 1-month and 1-year post-lung transplant.

\section{Central Message}

Depressed IgA before lung transplant predisposes recipients to seromucous infections after transplant, suggesting increased vigilance in monitoring for, and prophylaxing against, such infections.

\section{Perspective}

Immunoglobulin A ( $\operatorname{Ig} \mathrm{A})$ is important in defending against microbial colonization and invasion at seromucous membranes. We find that IgA deficiency in lung transplant candidates predisposes them to seromucous infections after transplantation. This suggests vigilance in monitoring for, and prophylaxis against, infection in this high-risk population.

See Editorial Commentary page 892.

See Editorial page 880 .
Infection is an important cause of early morbidity and mortality after lung transplantation. Immunoglobulin G (IgG) mediates serum defense, with depressed posttransplant

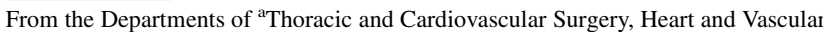
Institute, ${ }^{\mathrm{b}}$ Infectious Disease, Medicine Institute, ${ }^{\mathrm{c}}$ Pulmonary, Allergy, and Critical Care Medicine, Respiratory Institute, and ${ }^{\mathrm{d}}$ Quantitative Health Sciences, Research Institute, Cleveland Clinic, Cleveland, Ohio.

This study was funded in part by the Daniel and Karen Lee Endowed Chair in Thoracic Surgery; the Macon and Joan Brock Endowed Chair in Lung Transplant; the Peter and Elizabeth C. Tower and Family Endowed Chair in Cardiothoracic Research, the Buoncore Family Endowed Chair in Lung Transplantation; the Drs Sidney and Becca Fleischer Heart and Vascular Education Chair; and James and Sharon Kennedy, the Slosburg Family Charitable Trust, Stephen and Saundra Spencer, and Martin Nielsen.
}

IgG levels a risk factor for posttransplant infection. ${ }^{1-5}$ However, the majority of these infections occur across seromucous membranes (pulmonary, urinary tract,

\footnotetext{
Current address of R. K. Avery: Division of Infectious Diseases, Johns Hopkins University, Baltimore, Md.

Received for publication June 21, 2017; revisions received March 6, 2018; accepted for publication March 10, 2018; available ahead of print May 18, 2018.

Address for reprints: Sudish C. Murthy, MD, PhD, Department of Thoracic and Cardiovascular Surgery, Cleveland Clinic, 9500 Euclid Ave/Mail Stop J4-1, Cleveland, OH 44195 (E-mail: murthys1 @ ccf.org). $0022-5223 / \$ 36.00$

Copyright (C) 2018 Published by Elsevier Inc. on behalf of The American Association for Thoracic Surgery

https://doi.org/10.1016/j.jtcvs.2018.03.165
} 


\section{Abbreviations and Acronyms \\ $\mathrm{CMV}=$ cytomegalovirus \\ $\operatorname{Ig} \mathrm{A}=$ immunoglobulin $\mathrm{A}$ \\ $\mathrm{IgG}=$ immunoglobulin $\mathrm{G}$ \\ IRB = institutional review board}

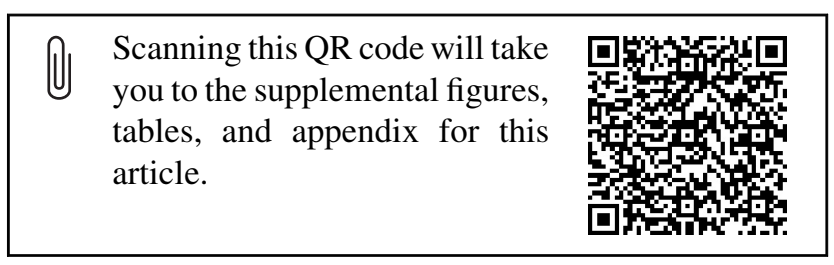

gastrointestinal, and sinus), and immunoglobulin A ( $\operatorname{Ig} \mathrm{A})$ defends against seromucous membrane microbial colonization and invasion. ${ }^{6}$ Accordingly, we hypothesized that decreased pretransplant $\operatorname{IgA}$ levels might place lung transplant recipients at increased risk for seromucousrelated infections early after transplant independent of $\mathrm{IgG}$ and pose a risk factor for posttransplant adverse outcomes.

Our objectives were therefore to discover any association of pretransplant IgA (and IgG) levels with seromucous infections occurring early after lung transplantation and to determine the association between pretransplant immunoglobulin levels and posttransplant survival.

\section{PATIENTS AND METHODS \\ Patients}

From January 2000 to July 2010, 677 adults age 18 years and older underwent primary lung transplantation at Cleveland Clinic, exclusive of heart-lung transplant. Of these, immunoglobulins were measured preoperatively in 538 based on existing care paths. Mean age at transplant was $54 \pm 12$ years, and $58 \%$ were men (Table 1 ). Primary pulmonary diagnosis was obstructive disease in $46 \%$ and restrictive lung disease in $38 \%$. Data used in this study were approved for use in research by the institutional review board (IRB; date and no. of IRB approval: IRB 4927 UTD January 24, 2018, and IRB 06-167 Transplant Registry January 27, 2018), with patient consent waived.

\section{Immunoglobulins}

Of the 538 patients, $429(80 \%)$ had pretransplant $\operatorname{IgA}$ measured $(\operatorname{IgA}$ group), and 488 (90\%) had pretransplant IgG measured (IgG group); both were measured in $257(48 \%)$. For the most part, these levels were measured at screening for listing as standard of care; however, the measurement taken closest to transplantation was used for analyses (Figure E1). Pretransplant IgA levels ranged 100 -fold, from 7 to $780 \mathrm{mg} \cdot \mathrm{dL}^{-1}$, median 200 (Figure E2, A); pretransplant IgG levels ranged 10-fold, from 296 to $2810 \mathrm{mg} \cdot \mathrm{dL}^{-1}$, median 970 (Figure E2, B). Lower limits of normal (not of detection) for our laboratory are $70 \mathrm{mg} \cdot \mathrm{dL}^{-1}$ for $\mathrm{IgA}$ and $600 \mathrm{mg} \cdot \mathrm{dL}^{-1}$ for IgG.

\section{Immunosuppression}

The immunosuppression regimen consisted of induction methylprednisolone $\left(7.5 \mathrm{mg} \cdot \mathrm{kg}^{-1}\right.$ up to $\left.1 \mathrm{~g}\right)$ and maintenance triple-drug therapy (calcineurin inhibitor [cyclosporine from 1990 to 2001; tacrolimus from $2001 \mathrm{on}$ ], antimetabolite [azathioprine from 1990 to 2001; mycophenolate from $2001 \mathrm{on}$ ], and glucocorticoid [prednisolone $5 \mathrm{mg}$ daily after 6 weeks). Antithymocyte globulin and OKT3 were infrequently used as induction agents.

\section{Infection Prophylaxis}

Bacterial prophylaxis after lung transplantation consisted of cefuroxime 1.5 g every 8 hours $\times 3$ doses and vancomycin 1 g every 12 hours $\times 2$ doses for the first 24 hours. Patients who were allergic to penicillin received vancomycin $1 \mathrm{~g}$ every 12 hours $\times 2$ and ciprofloxacin $400 \mathrm{mg}$ intravenously every 12 hours $\times 4$. Duration of antibacterial prophylaxis was not influenced by pretransplant immunoglobulin levels. Patients received posttransplant antimicrobials directed against specific pathogens based on cultures of donor and recipient airway swabs and also against known pretransplant colonizing bacterial organisms in patients with cystic fibrosis and bronchiectasis.

Fungal prophylaxis consisted of inhaled amphotericin or inhaled liposomal amphotericin starting immediately posttransplant and continued until healing of the anastomosis, as well as oral itraconazole for 18 months. Patients who developed colonization with aspergillus or other molds on surveillance bronchoalveolar lavage cultures were switched to voriconazole or posaconazole.

Prophylaxis for Pneumocystis jiroveci (carinii) was administered lifelong, usually with trimethoprim-sulfamethoxazole (unless sulfa-allergic, in which case patients received dapsone, atovaquone, or inhaled pentamidine).

Cytomegalovirus (CMV) prophylaxis was with ganciclovir (until 2004) and valganciclovir after that, most for 3 to 6 months, depending on donor and recipient serostatus. Some patients participated in a multi-institutional randomized trial of 3 versus 12 months of valganciclovir. ${ }^{7}$ Until 2005, donor-positive, recipient-negative CMV patients received CMV hyperimmune globulin as part of a clinical trial, $150 \mathrm{mg} \cdot \mathrm{kg}^{-1}$ at weeks $0,2,4,6$, and 8 and $100 \mathrm{mg} \cdot \mathrm{kg}^{-1}$ at weeks 12 and 16 posttransplantation, unless enrolled in a clinical trial. ${ }^{7}$ For the analysis of the relationship of level to infectious complications, patients in the IgG group were censored at time of postoperative administration of CMV hyperimmune globulin $(n=25)$.

\section{Definitions of Infections}

The focus of this study was post-transplant seromucous infections occurring during the first post-transplant year. Occurrence of every infection was entered prospectively into our Electronic Data Interface for Transplantation (EDIT) database (Management Science Associates, Inc., Pittsburgh, Pa) by our transplant coordinators at the time they were recognized. Every infection before and after lung transplantation was then adjudicated personally and in detail by a transplant infectious disease specialist (R.K.A.).

Seromucous infection was defined as an infection occurring on exposed external or luminal surfaces coated with seromucous secretions. ${ }^{6}$ Specific seromucous infections were defined as follows:

- Pulmonary infection: Positive bronchoalveolar lavage, induced sputum culture with coincident new pulmonary findings on radiographic imaging, purulent sputum ( $\geq 25$ leukocytes per microscopic field) with positive cultures but without new pulmonary findings on radiographic imaging, or adjudicated clinical diagnosis in the absence of culture data.

- Urinary tract infection: Positive urine culture with at least 5 leukocytes per microscopic field or treated symptomatic bacteriuria and adjudicated as such.

- Gastrointestinal infection: Nausea, vomiting, or diarrhea of suspected or proven infectious etiology, as adjudicated.

- Sinus infection: Radiographic evidence of sinus air-fluid levels on computed tomography scan severe enough to require hospital admission of an outpatient or occurring in an already-hospitalized patient, as adjudicated. 
TABLE 1. Patient and procedure characteristics (total $\mathbf{n}=\mathbf{5 3 8}$ )

\begin{tabular}{|c|c|c|}
\hline Characteristic & $\mathbf{n}^{*}$ & No. $(\%)$ or mean \pm SD \\
\hline \multicolumn{3}{|l|}{ Recipient } \\
\hline \multicolumn{3}{|l|}{ Demographics } \\
\hline Female & 538 & $224(42)$ \\
\hline Age at transplant, $y$ & 538 & $54 \pm 12$ \\
\hline Body mass index, $\mathrm{kg} \cdot \mathrm{m}^{-2}$ & 538 & $25 \pm 5.2$ \\
\hline \multicolumn{3}{|l|}{ Primary diagnosis } \\
\hline $\begin{array}{l}\text { Cystic fibrosis and } \\
\text { immunodeficiency }\end{array}$ & 538 & $61(11)$ \\
\hline Obstructive disease & 538 & $250(46)$ \\
\hline Pulmonary arterial disease & 538 & $16(3.0)$ \\
\hline Restrictive lung disease & 538 & $203(38)$ \\
\hline Nonspecified & 538 & $8(1.5)$ \\
\hline \multicolumn{3}{|l|}{ Pulmonary function } \\
\hline FEV1, \% $\dagger$ & 525 & $32 \pm 19$ \\
\hline FVC, $\% \dagger$ & 525 & $49 \pm 16$ \\
\hline FEV1/FVC $\dagger$ & 525 & $0.70 \pm 0.38$ \\
\hline Total lung capacity, L & 538 & $6.0 \pm 1.0$ \\
\hline \multicolumn{3}{|l|}{ Serology, immunology } \\
\hline \multicolumn{3}{|l|}{ Blood type } \\
\hline A & 538 & $214(40)$ \\
\hline $\mathrm{AB}$ & 538 & $22(4.1)$ \\
\hline B & 538 & $62(12)$ \\
\hline $\mathrm{O}$ & 538 & $240(45)$ \\
\hline $\mathrm{Rh}+$ & 532 & $445(84)$ \\
\hline PRA $>10 \%$ & 365 & $57(16)$ \\
\hline \multicolumn{3}{|l|}{ Serology before transplant } \\
\hline Cytomegalovirus & 522 & $265(51)$ \\
\hline Epstein-Barr virus & 487 & 335 (69) \\
\hline \multicolumn{3}{|l|}{ Pretransplant status } \\
\hline 6-min walk, feet & 459 & $1000 \pm 350$ \\
\hline PA systolic pressure, $\mathrm{mm} \mathrm{Hg}$ & 480 & $41 \pm 15$ \\
\hline $\mathrm{PA}$ diastolic pressure, $\mathrm{mm} \mathrm{Hg}$ & 461 & $19 \pm 9.2$ \\
\hline PA mean pressure, $\mathrm{mm} \mathrm{Hg}$ & 461 & $26 \pm 11$ \\
\hline \multicolumn{3}{|l|}{ Comorbidity } \\
\hline Diabetes & 502 & $73(15)$ \\
\hline Hypertension & 505 & $104(21)$ \\
\hline History of smoking & 538 & $247(46)$ \\
\hline Creatinine, $\mathrm{mg} \cdot \mathrm{dL}^{-1}$ & 531 & $0.80 \pm 0.75$ \\
\hline \multicolumn{3}{|l|}{ Donor } \\
\hline \multicolumn{3}{|l|}{ Demographics } \\
\hline Female & 538 & $266(49)$ \\
\hline Age at harvest, y & 535 & $38 \pm 15$ \\
\hline Total lung capacity, L & 535 & $5.9 \pm 1.2$ \\
\hline \multicolumn{3}{|l|}{ Serology, immunology } \\
\hline \multicolumn{3}{|l|}{ Blood type } \\
\hline A & 538 & $163(30)$ \\
\hline $\mathrm{AB}$ & 538 & $10(1.9)$ \\
\hline B & 538 & $61(11)$ \\
\hline $\mathrm{O}$ & 538 & $295(55)$ \\
\hline $\mathrm{Rh}+$ & 481 & $408(85)$ \\
\hline Cytomegalovirus & 536 & $314(59)$ \\
\hline Epstein-Barr virus & 356 & $260(73)$ \\
\hline
\end{tabular}

TABLE 1. Continued

\begin{tabular}{lcc}
\hline \multicolumn{1}{c}{ Characteristic } & $\mathbf{n}^{*}$ & No. $(\%)$ or mean \pm SD \\
\hline Cause of death & & \\
$\quad$ Anoxia & 538 & $60(11)$ \\
Cerebral hemorrhage & 538 & $0(0)$ \\
Stroke & 538 & $236(44)$ \\
Head trauma & 538 & $223(41)$ \\
Other & 538 & $15(2.8)$ \\
Procedure & & \\
Support & & \\
$\quad$ Maximum ischemic time, min & 470 & $280 \pm 88$ \\
$\quad$ Cardiopulmonary bypass & 535 & $265(50)$ \\
Transplant & & \\
$\quad$ Double lung & 538 & $295(55)$ \\
$\quad$ Single lung & 538 & $243(45)$ \\
$\quad$ Right lung only & 538 & $118(22)$ \\
Left lung only & 538 & $125(23)$
\end{tabular}

$\overline{S D \text {, Standard deviation; } F E V I, \% \text {, forced expiratory volume in } 1 \text { second (percent of }}$ predicted); $F V C, \%$, forced vital capacity (percent of predicted); $P R A$, panel reactive antibody; $P A$, pulmonary artery. *Patients with data available. $†$ National Health and Nutrition Examination Survey (NHANES) normalized.

\section{Follow-up}

Patients were followed during the first posttransplant year for all infectious complications, with complete follow-up in $98 \%$ of those still alive at the end of 1 year. A total of 479 patient-years of follow-up to 1 year were available for analysis. In addition, these patients were followed systematically beyond 1 year for vital status, median 3.0 years. For the latter, 2008 patient-years of follow-up data were available for analysis; $25 \%$ of living patients were followed more than 6.6 years and $10 \%$ more than 8.8 years.

\section{Data Analysis}

SAS version 9.2 (SAS Institute, Cary, NC) and $\mathrm{R}^{8}$ were used for statistical analyses.

Seromucous infections. Posttransplant seromucous infections were analyzed as repeating events using Nelson's cumulative event function for nonparametric estimates ${ }^{9-11}$ and multiphase hazard function methodology for parametric estimates. ${ }^{12}$ (For additional details, see http://www.lerner.ccf.org/qhs/software/hazard.) In addition, to answer the question of whether one seromucous infection begets another, a modulated renewal analysis was performed. ${ }^{13}$ In such an analysis, patients experiencing a first seromucous infection are restarted at new time zero and followed for a second seromucous infection. Those experiencing a second are restarted at another new time zero and followed to a third infection, etc.

A nonproportional hazards method was chosen to identify risk factors for seromucous infections because of the marked early peak of risk followed by a near-constant risk, as will be shown, which suggests that different risk factors may be influential in the 2 components of risk resolved in this analysis. To maximize the use of available immunoglobulin data, separate multivariable analyses of seromucous infections were performed for the $\mathrm{IgA}$ and $\mathrm{IgG}$ groups. Risk factors for these infections were selected by bagging ${ }^{14-16}$ - an unsupervised machine-learning method for variable selection-for each hazard phase using 500 bootstrap samples (Appendix E1). Variables significant at $P \leq .05$ in $50 \%$ or more of 500 analyses were considered reliable risk factors. Because lung transplant often occurs long after listing (and in our case, sometimes long after immunoglobulins were measured), we not only included the interval between immunoglobulin measurement and transplantation in these multivariable analyses but 
also an interaction term between immunoglobulin level and that interval to test the hypothesis that the association of outcomes and immunoglobulin level diminished as the interval lengthened.

Because the shape of the relationship of immunoglobulin levels and seromucous infection was unknown, we performed a complementary analysis using random survival forests, ${ }^{17}$ a completely nonparametric method. This machine-learning method does not eliminate any variables, but ranks the importance of variables on the basis of reducing prediction error for outcomes in the roughly one-third of patients not selected for a given bootstrapped data set used to build a time-to-event (seromucous infection) tree. ${ }^{18}$ We constructed 5000 trees for this analysis. The resulting random survival forest was then used to estimate the relationship of the immunoglobulins to seromucous infection and, with another forest, to survival after adjusting for all 72 variables considered in the analysis (partial dependency plots). ${ }^{19}$

Survival. Survival was assessed nonparametrically by the KaplanMeier method and parametrically by a multiphase hazard model. ${ }^{12}$ Risk factors for death were selected using the strategy described in the previous text.

Missing values. For parametric modeling, 5-fold multiple imputation of missing values was based on the Markov chain Monte Carlo technique assuming missing at random. ${ }^{20}$ This was implemented with PROC MI, and PROC MIANALYZE was used to generate final parametric model estimates and their variance-covariance matrix. Random survival forest methodology has a built-in robust missing value algorithm for imputation. $^{17,21}$

Presentation. Continuous variables are summarized by mean \pm standard deviation or median and 15th and 85th percentiles for skewed distributions, consistent with \pm 1 standard deviation. Categorical variables are summarized by frequency and percentage. Confidence limits equivalent to \pm 1 standard error $(68 \%)$ are used to express uncertainty of nonparametric and parametric estimates. These same 15 th and 85 th percentiles are used to illustrate the association of immunoglobulin levels with infection and survival.

\section{RESULTS \\ Seromucous Infections}

A total of 397 seromucous infections were observed in 247 patients within the first year after lung transplantation. One hundred forty-eight patients presented with a single infection, 68 with 2, 20 with 3 , and 11 with 4 to 7 . Seventy-five percent of these were pneumonia, 13\% urinary tract infections, $9.8 \%$ gastrointestinal infections, and $2.3 \%$ sinus infections (Table E1). The organisms were bacterial in $77 \%$, fungal in $9.3 \%$, and viral in $5.5 \%$; cultures were negative in $7.8 \%$ and unavailable in $0.25 \%$ (Table E2). Cumulative incidence of seromucous infection was 41 per 100 patients by 3 months after transplantation and 80 at 12 months (Figure 1). The corresponding instantaneous risk of seromucous infection exhibited an early peaking hazard phase by 2 weeks after transplant, followed by a nearly constant risk (Figure 1 , inset). Patients experiencing a first seromucous infection were approximately at the same risk of a second infection $(P>.2$; Figure E3), and this was true after each subsequent infection.

\section{Seromucous Infections and Immunoglobulins}

IgA group. In the IgA group (429 patients), 196 (46\%) experienced 320 seromucous infections (Tables E1 and E2). When patients were stratified according to $\operatorname{IgA}$ into the lowest versus highest 15 th percentiles, those with $\operatorname{IgA}$ levels of $120 \mathrm{mg} \cdot \mathrm{dL}^{-1}$ or less-levels within the normal range for our laboratory-experienced distinctly more

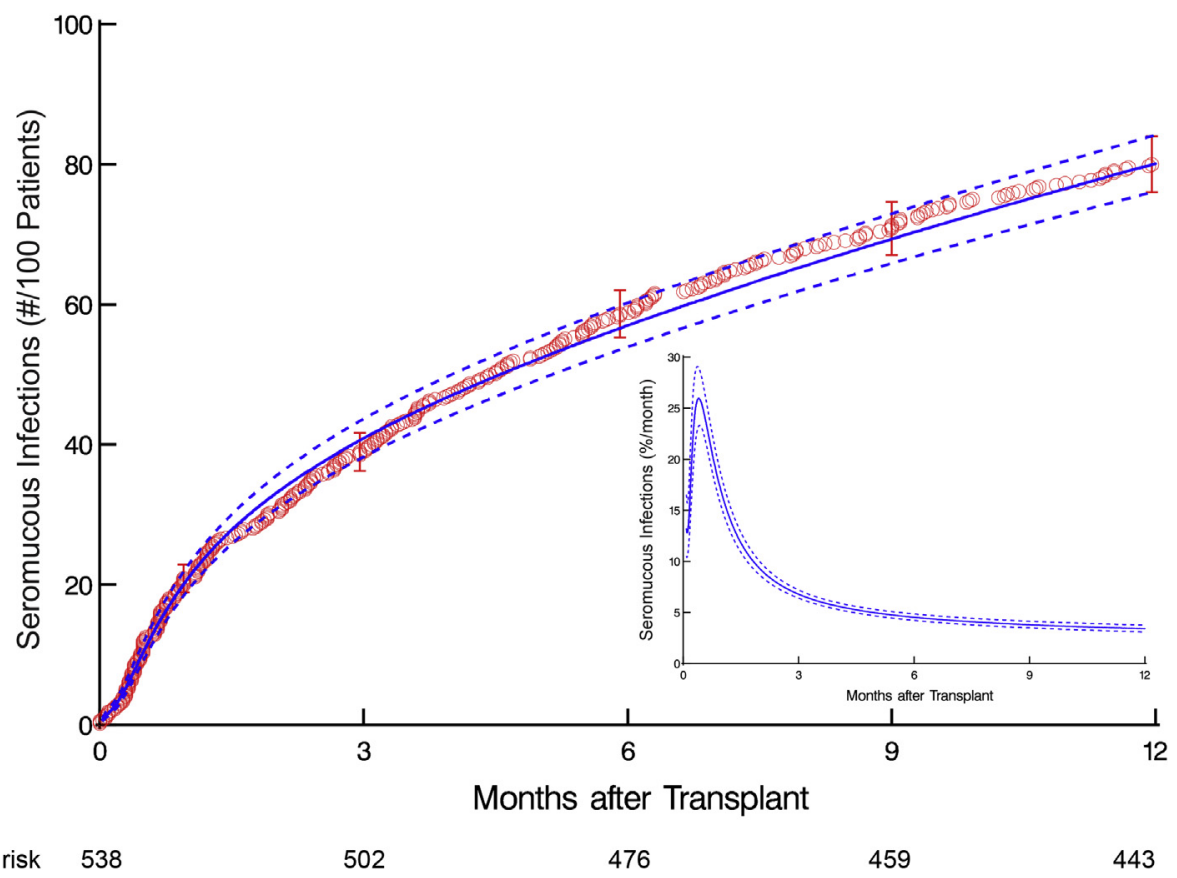

FIGURE 1. Cumulative incidence of seromucous infections occurring during the first year after lung transplantation. Each circle represents an infection and vertical bars $68 \%$ confidence limits (CL); numbers below the axis are patients remaining at risk. Solid line is parametric estimate enclosed within a dashed $68 \%$ confidence band equivalent to 1 standard error. Inset is instantaneous risk (hazard function) enclosed within $68 \%$ CLs. 

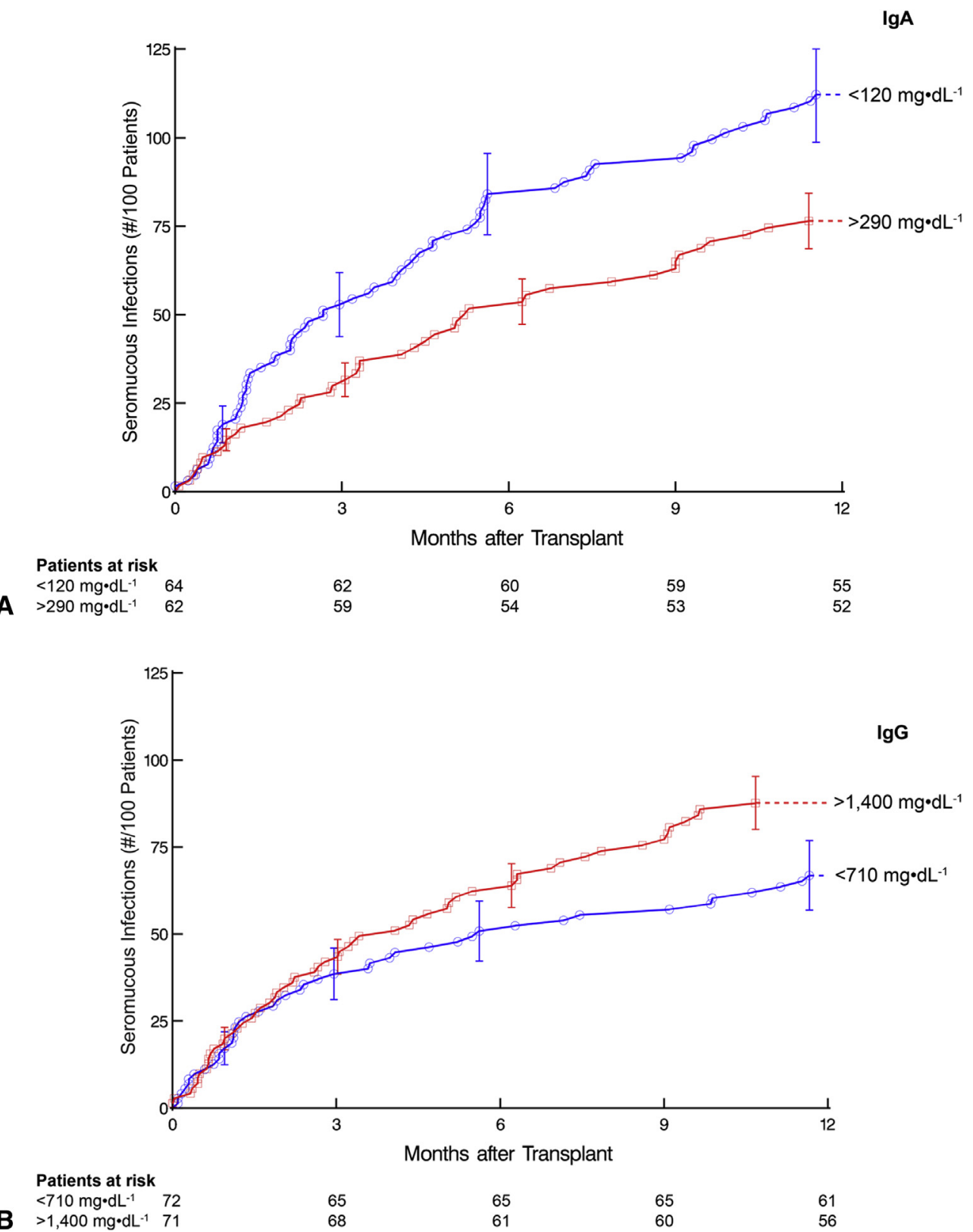

FIGURE 2. Seromucous infection after lung transplantation in the lowest and highest 15 th percentiles of pretransplant immunoglobulin levels. Cumulative number of infections per 100 patients is expressed on the vertical axis. Each symbol represents an event positioned by nonparametric estimate, vertical bars represent asymmetric $68 \%$ confidence limits, and numbers below the horizontal axis are patients remaining at risk. A, Immunoglobulin A (IgA). B, Immunoglobulin $\mathrm{G}(\operatorname{Ig} G)$.

infections than those with levels greater than $290 \mathrm{mg} \cdot \mathrm{dL}^{-1}$ (Figure $2, A)$. Indeed, only 7 patients $(1.6 \%)$ had IgA levels below the lower limit of normal $\left(70 \mathrm{mg} \cdot \mathrm{dL}^{-1}\right)$. The association of $\operatorname{IgA}$ levels with seromucous infections increased with time after transplant, as demonstrated in the multivariable analysis of these infections, which shows the effect of IgA in the intermediate (constant) hazard phase (Table 2 and Figure 2,A). Of all 72 variables examined in relation to seromucous infection using random forests, preoperative IgA was hierarchically found to have the greatest importance in predicting seromucous infections (Figure E4). Specifically, values of $\operatorname{IgA}$ below $200 \mathrm{mg} \cdot \mathrm{dL}^{-1}$ were associated with a nearly linear increase in risk of infection, whereas those above that level showed no relationship (Figure 3). Longer interval between IgA measurement and lung transplant somewhat diminished the association between $\operatorname{IgA}$ 
TABLE 2. Risk factors for seromucous infections in IgA group $(\mathrm{n}=429)$

\begin{tabular}{lcl}
\hline \multicolumn{1}{c}{ Factor } & Coefficient \pm SE & \multicolumn{1}{c}{$\boldsymbol{P}$} \\
\hline Early phase & & \\
IgA* & $-0.13 \pm 0.21$ & .6 \\
Diagnosis other than restrictive & $0.98 \pm 0.28$ & .0006 \\
$\quad$ lung disease & $-0.44 \pm 0.13$ & .001 \\
Higher FEV1 (\% of predicted)/ & & \\
$\quad$ FVC (\% of predicted) ratio $\dagger$ & & \\
Intermediate phase & $0.069 \pm 0.027$ & .01 \\
Lower IgA $\ddagger$ & $0.20 \pm 0.06$ & .001 \\
Younger age $\S$ & $-0.00064 \pm 0.00027$ & .02 \\
Shorter 6-min walk, feet & $0.69 \pm 0.28$ & .02 \\
EBV: donor-recipient mismatch & \\
\hline
\end{tabular}

$S E$, Standard error; $I g A$, immunoglobulin $\mathrm{A} ; F E V I$, forced expiratory volume in $1 \mathrm{sec}-$ ond, $F V C$, forced vital capacity; $E B V$, Epstein-Barr virus. ${ }^{*} \log (\operatorname{IgA}), \operatorname{logarithmic}$ transformation. $\dagger[1 /(\mathrm{FEV} 1(\%$ of predicted $) / \mathrm{FVC}$ ( $\%$ of predicted) $]$, inverse transformation. $\ddagger(20 / \mathrm{IgA})$, inverse transformation. $\S(50 / \mathrm{age})^{2}$, inverse squared transformation.

level and seromucous infection, but not by much (Figure E5) and not statistically significantly (P[early phase $]=.18 ;$ P intermediate phase $]=.11)$. Of the 429 patients, 20 had $2 \operatorname{IgA}$ measurements and 5 had 3 or more (Figure E6); among these 25 (5.8\% of total), those with lower initial values tended to have somewhat greater values on repeated testing, and those with greater initial values had somewhat lower values on repeated testing $(P$ value for trend test $=.11$ ).

Variables associated with higher levels of pretransplant IgA were related to the pulmonary disease leading to lung transplantation (Table E3). Older patients and those with obstructive disease had the lowest pretransplant IgA levels and those with restrictive lung disease and cystic fibrosis or immunodeficiency disease the greatest (Figure E7).

IgG group. In the IgG group (488 patients), 218 (45\%) experienced 349 seromucous infections during the first year after lung transplantation (Tables E1 and E2). When patients were stratified according to pretransplant $\operatorname{IgG}$ into the lowest versus highest 15 th percentiles, those with pretransplant IgG levels greater than $1400 \mathrm{mg} \cdot \mathrm{dL}^{-1}$ experienced slightly more seromucous infections than those with levels of $710 \mathrm{mg} \cdot \mathrm{dL}^{-1}$ or less, but with overlapping confidence limits (Figure 2, $B$ ). By multivariable analysis, pretransplant $\mathrm{IgG}$ level was not associated with seromucous infections $(P \geq .6$, Table E4).

\section{Survival and Immunoglobulin Levels}

Overall survival at 1 year and 5 years was $84 \%$ and $50 \%$, respectively. Lower pretransplant IgA level (Table 3), but not IgG level (Table E5), was a persistent risk factor for mortality throughout follow-up $(P=.006$; Figure 4$)$.

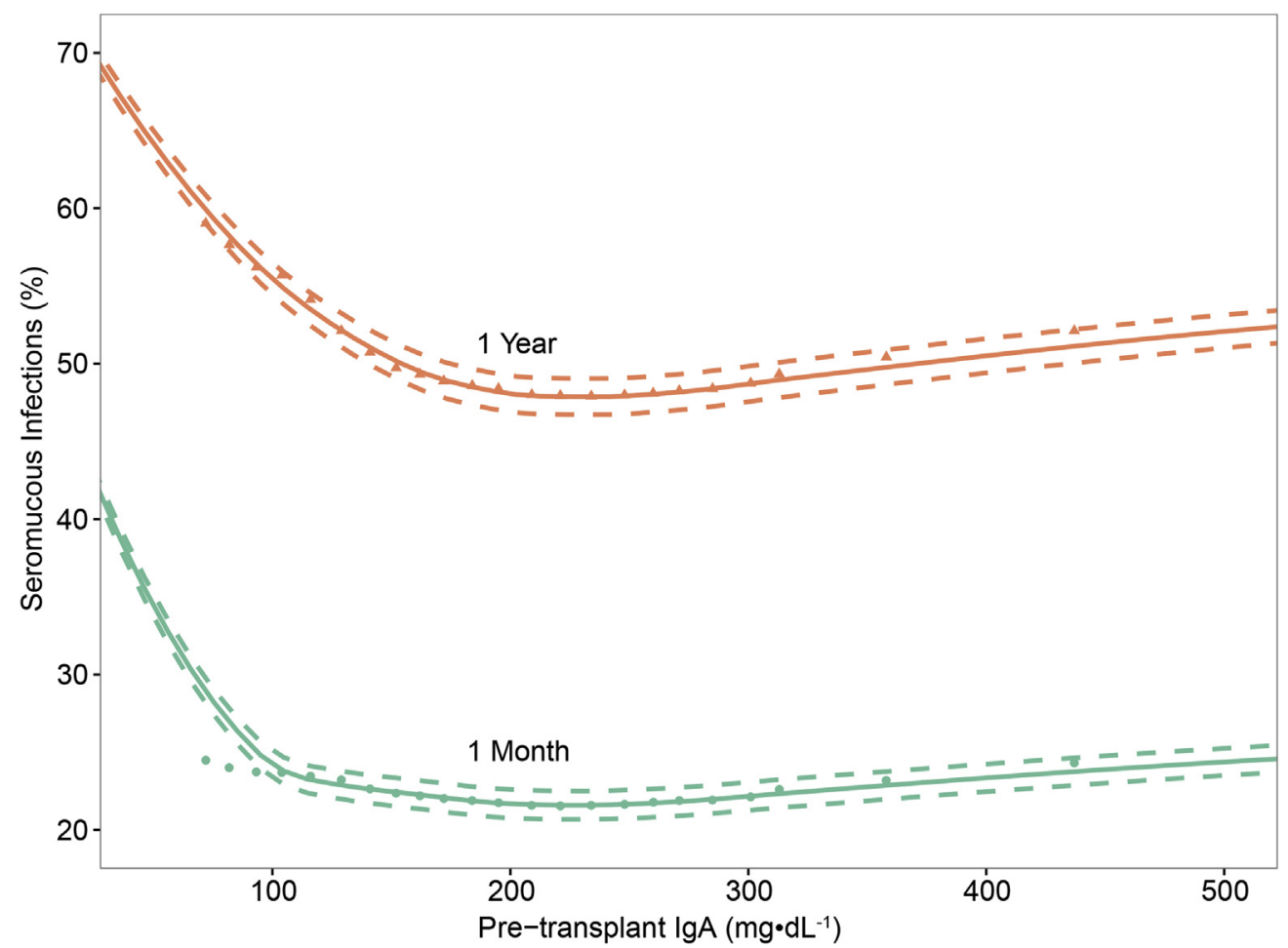

FIGURE 3. Partial dependency graph of pretransplant IgA level and probability of infection at 1 month and 1 year after lung transplant. Symbols and solid lines represent risk-adjusted estimates based on random survival forest methodology, and dashed lines are $68 \%$ confidence limits. IgA, Immunoglobulin A. 


\section{DISCUSSION \\ Principal Findings}

In lung transplant recipients, lower levels of pretransplant $\mathrm{IgA}$, but not $\mathrm{IgG}$, are associated with greater risk of early seromucous infections, particularly pneumonia, and this appears to translate into lower posttransplant survival in the short and long term.

\section{Results in Context}

There is no doubt that many variables influence occurrence of posttransplant infection. However, in this paper, we focused on the possibility of pretransplant susceptibility (or predisposition) to posttransplant infection.

IgA deficiency before lung transplantation has not been well studied, although it has been suggested that posttransplant $\operatorname{Ig}$ A deficiency is associated with increased community-acquired pneumonia, invasive fungal infection, sepsis, and death. ${ }^{5,22}$ This is hypothesized to be secondary to weakened seromucous defenses. In our study, we observed a clear incremental risk of seromucous infections early after lung transplantation in patients with pretransplant $\operatorname{IgA}$ levels below about $200 \mathrm{mg} \cdot \mathrm{dL}^{-1}$. Although the majority of these infections were bacterial pneumonias, more than $10 \%$ were secondary to fungal and viral pathogens. Few seromucous barriers were spared these infections: gastrointestinal, central airway, and urinary tract were also involved in patients with lower pretransplant IgA levels. This confirms the central role of IgA in seromucous defense throughout the body. ${ }^{6}$

\section{Pretransplant IgA Levels}

Based on our modulated renewal analysis, serial posttransplant infections occurring in patients with pretransplant low serum IgA levels do so as independent events. This then discounts the possibility that just a small number of patients with low IgA levels are responsible for the sizeable effect of IgA levels on seromucous infection after lung transplant.

Moreover, type of end-stage lung disease is associated with pretransplant $\operatorname{IgA}$ level, with obstructive disease patients being more often deficient. Interestingly, higher levels of IgA have been found in patients with interstitial lung disease (idiopathic pulmonary fibrosis), and higher levels of $\operatorname{Ig} \mathrm{A}$ in nontransplant settings are associated with greater mortality. ${ }^{23}$

Pretransplant IgA deficiency should be considered distinct from that occurring in the context of defined immunodeficiency syndromes (eg, severe combined immunodeficiency). As such, our IgA-deficient patient population is surprisingly poorly characterized. Instead, patients we have identified as at risk should not be considered as having selective IgA deficiency, or even a partial IgA deficiency, but rather as having a relative IgA deficiency based on current nomenclature. ${ }^{24}$

There have been scattered reports of increased cancer and severe transfusion reaction risks in the general population with relative $\operatorname{IgA}$ deficiency. ${ }^{25,26}$ In the liver transplant population, IgA-deficient recipients have higher mortality, with the cause of death more frequently being sepsis and opportunistic infections. ${ }^{22}$ For lung transplant patients, it has been demonstrated that serum IgA levels decline throughout the posttransplant period. ${ }^{5}$ Moreover, there is an association between decreasing posttransplant IgA levels and maintenance immunosuppression therapy. Importantly, lower IgA levels after lung transplant are associated with a greater risk of community-acquired respiratory viral infections, although declining posttransplant IgG levels, and not IgA, appear to correlate with bronchiolitis obliterans syndrome.

Although not the focus of this study, presence of low pretransplant IgG levels has been demonstrated to be a risk factor for posttransplant infection and death in heart and kidney transplantation. ${ }^{3,27}$ However, in lung transplantation, this is less clear because of a potential confounding effect of posttransplant immunosuppression. ${ }^{4}$ Only $10 \%$ of our patients had pretransplant IgG levels below $600 \mathrm{mg} \cdot \mathrm{dL}^{-1}$, similar to that previously reported. ${ }^{4}$ This was not statistically associated with occurrence of pneumonia in our study, although a paucity of patients were considered to be severely $\operatorname{IgG}$ deficient $\left(<400 \mathrm{mg} \cdot \mathrm{dL}^{-1}\right)$, a group that has been thought by others to be at risk of posttransplant pneumonia. ${ }^{4}$

\section{Survival}

We were somewhat surprised that relative deficiency of IgA reverberated throughout the entire posttransplant course and was not restricted to just the early posttransplant period. How could it be that a spot-check of IgA level, performed in some instances 2 years or more before transplant, could dictate the clinical course for a patient's entire followup? It makes most sense to us that the effect of pretransplant IgA is in the early course posttransplant, with a clear association with seromucous infection. We postulate that this rocky start for these patients continues in a downward spiral. However, we have no data to support this hypothesisgenerating conjecture.

\section{Recommendations and Future Directions}

These interesting findings expose the knowledge gaps in our current lung transplant management paradigms and ultimately raise far more questions than answers. Until this study, we frankly had not paid attention to pretransplant IgA levels, how they may influence posttransplant infections, and how they might alter clinical management before and after lung transplantation. We were so surprised by our findings that we repeated the study 3 times, adding more 
TABLE 3. Incremental risk factors for death in $\operatorname{IgA}$ group $(n=429)$

\begin{tabular}{lcl}
\hline \multicolumn{1}{c}{ Factor } & Coefficient \pm SE & \multicolumn{1}{c}{$\boldsymbol{P}$} \\
\hline Early phase & & \\
$\quad$ IgA* & $-0.061 \pm 0.25$ & .8 \\
Shorter 6-min walk, feet & $-0.0017 \pm 0.00058$ & .002 \\
Higher donor creatinine & $0.49 \pm 0.11$ & $<.0001$ \\
Constant phase & & \\
Lower IgA* & $0.10 \pm 0.036$ & .006 \\
Younger age $\dagger$ & $0.41 \pm 0.11$ & .0001 \\
Diagnosis other than cystic fibrosis & $0.95 \pm 0.48$ & .04 \\
$\quad$ & & \\
$\quad$ and immunodeficiency & $1.5 \pm 0.52$ & .003 \\
Larger body mass index $\ddagger$ & $-0.44 \pm 0.19$ & .02 \\
Lower donor creatinine $§$ & $0.42 \pm 0.16$ & .008 \\
Donor cytomegalovirus IgG & $0.58 \pm 0.18$ & .001 \\
\hline Single lung transplant &
\end{tabular}

$S E$, Standard error; $I g A$, immunoglobulin A; $I g G$, immunoglobulin G. *(200/IgA), inverse transformation. $\dagger(50 / \text { age })^{2}$, inverse squared transformation. $\ddagger($ Body mass index/ $40)^{2}$, squared transformation. §ूLog(donor creatinine), logarithmic transformation.

and more data, and the last time requesting expert adjudication of every infection documented in these patients after transplantation. By virtue of these findings, we believe that there is some merit in continuing routine pretransplant surveillance of $\operatorname{Ig}$ A serum levels (in addition to $\mathrm{IgG}$ ), and this should be a standard of care.

Specifically, given that there is some blunting of the effect of pretransplant $\operatorname{IgA}$ when measured at an extended interval before transplant-although still quite apparentupdating IgA serum levels at 6-month intervals after listing might allow us to identify the patients at highest risk for posttransplant seromucous infections.

The association of low pretransplant serum IgA level and seromucosal infection posttransplant, however, creates some amount of consternation and confusion regarding how to use these findings from this point forward. Should we augment IgA, and if so, how (we are unaware of any proven safe and effective method to do so)? How can we fortify seromucosal defenses for patients with documented low pretransplant serum IgA? Is a low serum IgA level a distinct immunologic deficiency or simply a marker for some other immune interplay that we have not yet discovered? Is pretransplant IgA level associated with subsequent development of posttransplant bronchiolitis obliterans syndrome, as is posttransplant IgA ${ }^{5}$ How do IgA levels change in the posttransplant state, and are levels meaninglessly altered by standard immunosuppression protocols? ? $^{28}$ Should peritransplant antibiotic prophylaxis be modified for lung transplant recipients with low serum IgA levels? Finally, what is the mechanism for the long-term effects on survival associated with pretransplant relative IgA deficiency? As is often the case, with increasing knowledge comes increasing uncertainty.

\section{Limitations}

Pretransplant immunoglobulins were measured with a focus on IgG levels and not IgA because of previous investigations demonstrating that hypogammaglobulinemia occurs

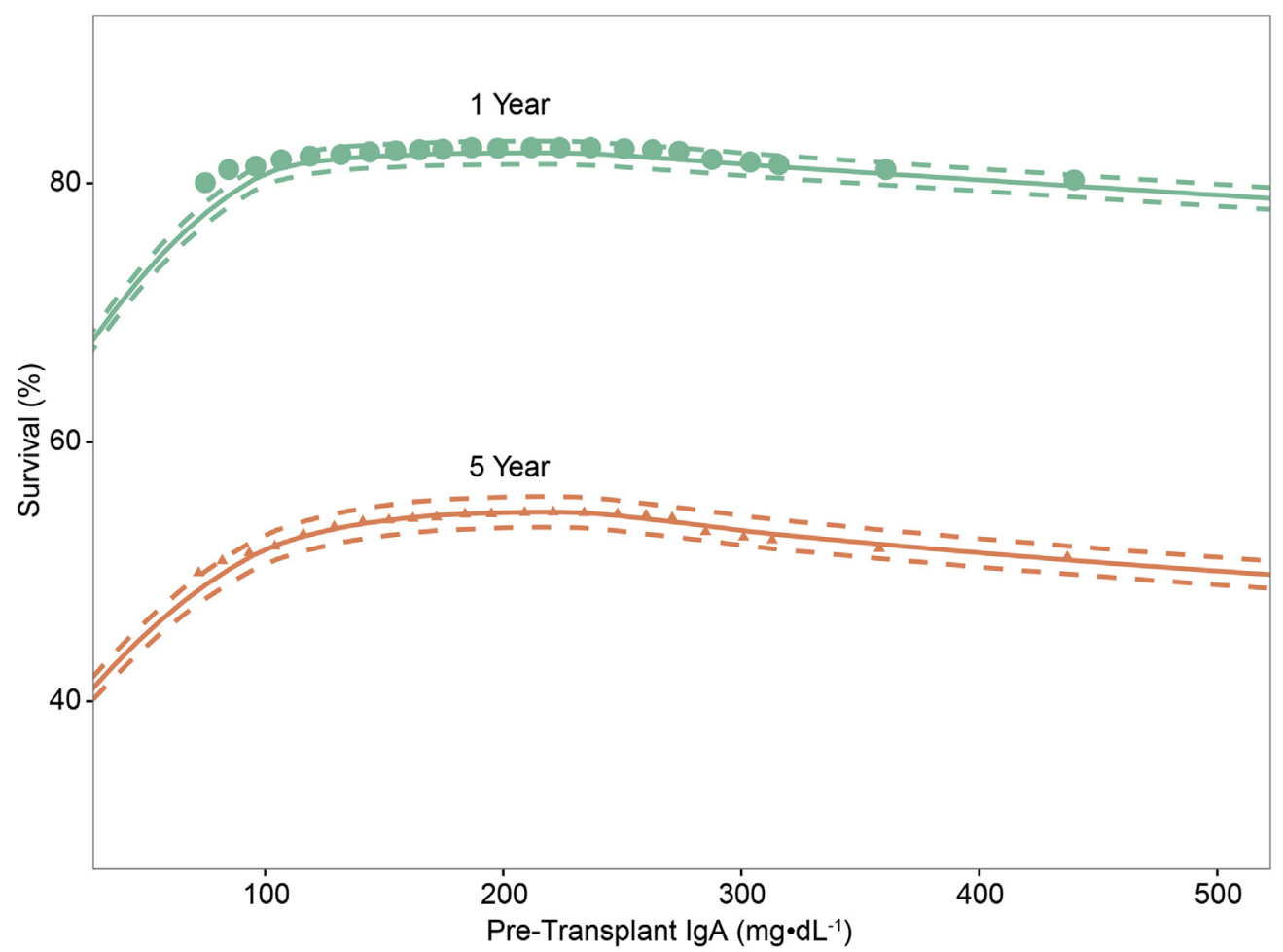

FIGURE 4. Partial dependency plot of pretransplant IgA and 1- and 5-year survival after lung transplant. Format is as in Figure 3. IgA, Immunoglobulin A. 
in transplant recipients. ${ }^{1}$ Fortunately for us, routine immunoglobulin panels included $\operatorname{IgA}$, and it was only well after the fact that we began to suspect any connection between pretransplant IgA levels and posttransplant seromucous infections. Thus, this was a retrospective study of prospectively collected data, with subsequent infection adjudication.

Conduct and interpretation of this study is complicated by several other factors. Because of uncertainty of donor-organ availability, the interval between pretransplant immunoglobulin assessment and transplant varied widely. Moreover, this single check in most patients may underappreciate fluctuations of levels in a given patient. However, among the $6 \%$ of patients in whom IgA was measured again, the level appeared to be generally stable. Furthermore, our screening for IgG and IgA levels was not perfect, and we were unable to capture information on $20 \%$ of our cohort. We do not know whether pretransplant assessment accurately reflects posttransplant levels of immunoglobulins. Moreover, we do not know the relationship between circulating and secretory $\operatorname{IgA} .^{29}$ Thus, we are unaware of the local status of secretory concentration of IgA, which appears to continue after lung transplant. ${ }^{29}$ How this might affect seromucous infections early posttransplant is unknown. Nor do we know the effects of immunosuppression. A small number of patients in this cohort were enrolled in trials to augment $\operatorname{IgG}$ levels, but none of these trials was instituted pretransplant when IgA was measured.

We purposely truncated investigation of infections at 1 year because we thought it unlikely that a spot measurement of pretransplant immunoglobulin would continue to influence posttransplant recovery in the long term. Consequently, we do not know potential protracted infectious morbidity that may be associated with these preoperative variables. We also recognize that many posttransplant variables co-evolve with infections. We have not assessed these time-varying covariables in this study.

\section{CONCLUSIONS}

Depressed levels of IgA before lung transplantation, but not IgG, are associated with both increased occurrence of seromucous infections early after lung transplantation and mortality throughout follow-up. These findings highlight the importance of a robust seromucous defense mechanism in protecting against posttransplant infection. It would appear prudent to identify IgA-deficient patients at listing and institute increased vigilance of monitoring for, and prophylaxis against, infection in this high-risk population.

\section{Conflict of Interest Statement}

Dr Avery: Site investigator on randomized clinical trials (study support only): Shire, Astellas Pharma, Chimerix, Merck, and Oxford Immunotec. Unpaid consultant to Shire regarding the investigational anti-CMV drug maribavir. She receives no personal financial remuneration from any company outside of study support for conducting randomized trials. All other authors have nothing to disclose with regard to commercial support.

The authors thank Tess Parry for editorial assistance.

\section{References}

1. Goldfarb NS, Avery RK, Goormastic M, Mehta AC, Schilz R, Smedira N, et al. Hypogammaglobulinemia in lung transplant recipients. Transplantation. 2001; 71:242-6.

2. Kawut SM, Shah L, Wilt JS, Dwyer E, Maani PA, Daly TM, et al. Risk factors and outcomes of hypogammaglobulinemia after lung transplantation. Transplantation. 2005;79:1723-6.

3. Sarmiento E, Rodriguez-Molina J, Munoz P, Fernandez-Yanez J, Palomo J, Fogueda M, et al. Decreased levels of serum immunoglobulins as a risk factor for infection after heart transplantation. Transplant Proc. 2005;37:4046-9.

4. Yip NH, Lederer DJ, Kawut SM, Wilt JS, D'Ovidio F, Wang Y, et al. Immunoglobulin G levels before and after lung transplantation. Am J Respir Crit Care Med. 2006;173:917-21.

5. Chambers DC, Davies B, Mathews A, Yerkovich ST, Hopkins PM. Bronchiolitis obliterans syndrome, hypogammaglobulinemia, and infectious complications of lung transplantation. J Heart Lung Transplant. 2013;32:36-43.

6. Delves PJ, Martin SJ, Burton DR, Roitt IM. Roitt's Essential Immunology. Hoboken, NJ: Wiley-Blackwell; 2012:50-1.

7. Palmer SM, Limaye AP, Banks M, Gallup D, Chapman J, Lawrence EC, et al. Extended valganciclovir prophylaxis to prevent cytomegalovirus after lung transplantation: a randomized, controlled trial. Ann Intern Med. 2010;152: 761-9.

8. R Development Core Team. R: A Language and Environment for Statistical Computing. Version 3.3.1 (2016-06-21). Vienna, Austria: R Foundation for Statistical Computing; 2016. Available at: http://www.R-project.org.

9. Nelson W. Applied Life Data Analysis. New York: John Wiley; 1982.

10. Nelson W. Theory and applications of hazard plotting for censored failure data. Technometrics. 1972;14:945-66.

11. Nelson W. Graphical analysis of system repair data. J Qual Technol. 1988;20: 24-35.

12. Blackstone EH, Naftel DC, Turner ME Jr. The decomposition of time-varying hazard into phases, each incorporating a separate stream of concomitant information. J Am Stat Assoc. 1986;81:615-24.

13. Kalbfleisch JD, Prentice RL. The Statistical Analysis of Failure Time Data. New York: Wiley; 1980.

14. Breiman L. Bagging predictors. Machine Learning. 1996;24:123-40.

15. Sauerbrei W, Schumacher M. A bootstrap resampling procedure for model building: application to the Cox regression model. Stat Med. 1992;11:2093-109.

16. Rajeswaran J, Blackstone EH. Identifying risk factors: challenges of separating signal from noise. J Thorac Cardiovasc Surg. 2017; 153:1136-8.

17. Ishwaran H, Kogalur UB, Blackstone EH, Lauer MS. Random survival forests. Ann Appl Statist. 2008;2:841-60.

18. Ishwaran H. Variable importance in binary regression trees and forests. Electron J Statist. 2007;1:519-37.

19. Ishwaran H, Kogalur UB. RandomForestSRC: random forests for survival, regression and classification (RF-SRC). R package version 2.1.0. Available at: http://cran.r-project.org.

20. Rubin DB. Multiple Imputation for Nonresponse in Surveys. New York: Wiley; 1987.

21. Tang F, Ishwaran H. Random forest missing data algorithms. Stat Anal Data Min. 2017;10:363-77.

22. Van Thiel DH, Finkel R, Friedlander L, Gavaler JS, Wright HI, Gordon R. The association of $\operatorname{IgA}$ deficiency but not $\operatorname{Ig} \mathrm{G}$ or IgM deficiency with a reduced patient and graft survival following liver transplantation. Transplantation. 1992; 54:269-73.

23. Ten Klooster L, van Moorsel CH, Kwakkel-van Erp JM, van Velzen-Blad H, Grutters JC. Immunoglobulin A in serum: an old acquaintance as a new prognostic biomarker in idiopathic pulmonary fibrosis. Clin Exp Immunol. 2015; 181:357-61.

24. Yel L. Selective IgA deficiency. J Clin Immunol. 2010;30:10-6.

25. Ludvigsson JF, Neovius M, Ye W, Hammarstrom L. IgA deficiency and risk of cancer: a population-based matched cohort study. J Clin Immunol. 2015;35: $182-8$. 
26. Anani W, Triulzi D, Yazer MH, Qu L. Relative IgA-deficient recipients have an increased risk of severe allergic transfusion reactions. Vox Sang. 2014;107:389-92.

27. Pollock CA, Mahony JF, Ibels LS, Caterson RJ, Waugh DA, Wells JV, et al. Immunoglobulin abnormalities in renal transplant recipients. Transplantation. 1989;47:952-6.

28. Wirsum C, Glaser C, Gutenberger S, Keller B, Unger S, Voll RE, et al. Secondary antibody deficiency in glucocorticoid therapy clearly differs from primary antibody deficiency. J Clin Immunol. 2016;36:406-12.
29. Bastian A, Tunkel C, Lins M, Bottcher H, Hirt SW, Cremer J, et al. Immunoglobulin A and secretory immunoglobulin A in the bronchoalveolar lavage from patients after lung transplantation. Clin Transplant. 2000;14: $580-5$.

Key Words: immunoglobulin A, immunoglobulin G, lung transplantation, seromucous infection 


\section{APPENDIX E1. VARIABLES CONSIDERED IN MULTIVARIABLE ANALYSES \\ Recipient}

Serology and immunology. Blood type (A, AB, B, O, $\mathrm{Rh}+$ ), panel reactive antibody, cytomegalovirus (CMV) serology, Epstein-Barr virus (EBV) serology, immunoglobulin A, immunoglobulin $\mathrm{G}$, interval from laboratory test to transplant (days).

Demographics. Age (years), sex, race, weight (kg), height $(\mathrm{cm})$, body surface area $\left(\mathrm{m}^{2}\right)$, body mass index $\left(\mathrm{kg} \cdot \mathrm{m}^{-2}\right)$.

Diagnosis. Cystic fibrosis and immunodeficiency, obstructive disease, pulmonary vascular disease, restrictive lung disease, nonspecified diagnosis.

Pulmonary function. Forced expiratory volume in $1 \mathrm{sec}-$ ond (percent of predicted, National Health and Nutrition Examination Survey normalized), forced vital capacity (percent of predicted, National Health and Nutrition Examination Survey normalized), forced expiratory volume in 1 second (percent of predicted)/forced vital capacity (percent of predicted) ratio.
Comorbidities. Diabetes (insulin treated, non-insulintreated), hypertension, smoking, creatinine $\left(\mathrm{mg} \cdot \mathrm{dL}^{-1}\right)$.

\section{Donor}

Demographics. Age (years), sex, race, weight (kg), height $(\mathrm{cm})$, body surface area $\left(\mathrm{m}^{2}\right)$, body mass index $\left(\mathrm{kg} \cdot \mathrm{m}^{-2}\right)$. Comorbidities. Hypertension, smoking, creatinine $\left(\mathrm{mg} \cdot \mathrm{dL}^{-1}\right)$.

Serology and immunology. Blood type (A, AB, B, O, $\mathrm{Rh}+$ ), CMV serology, EBV serology.

Cause of death. Anoxia, cerebral hemorrhage, central nervous system tumor, stroke, head trauma, other.

\section{Donor-Recipient Mismatch}

CMV donor-recipient mismatch, EBV donor-recipient mismatch, $\mathrm{Rh}$ donor-recipient mismatch, ABO donorrecipient mismatch.

\section{Procedure}

Maximum ischemic time (minutes), single or double lung transplant. 

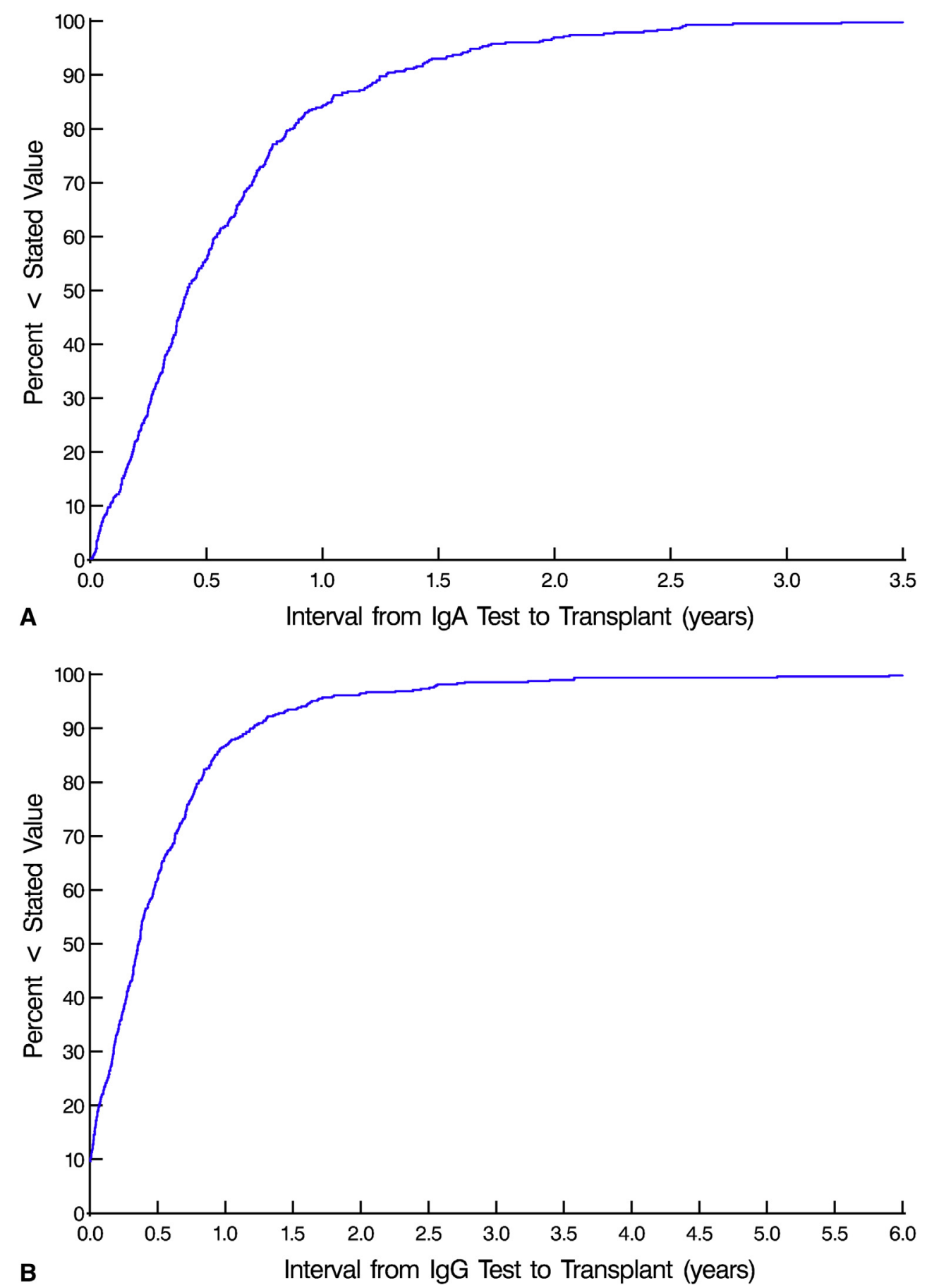

FIGURE E1. Cumulative distribution of intervals from immunoglobulin test to lung transplantation. A, Immunoglobulin A (IgA). B, Immunoglobulin G $(\operatorname{Ig} G)$. 

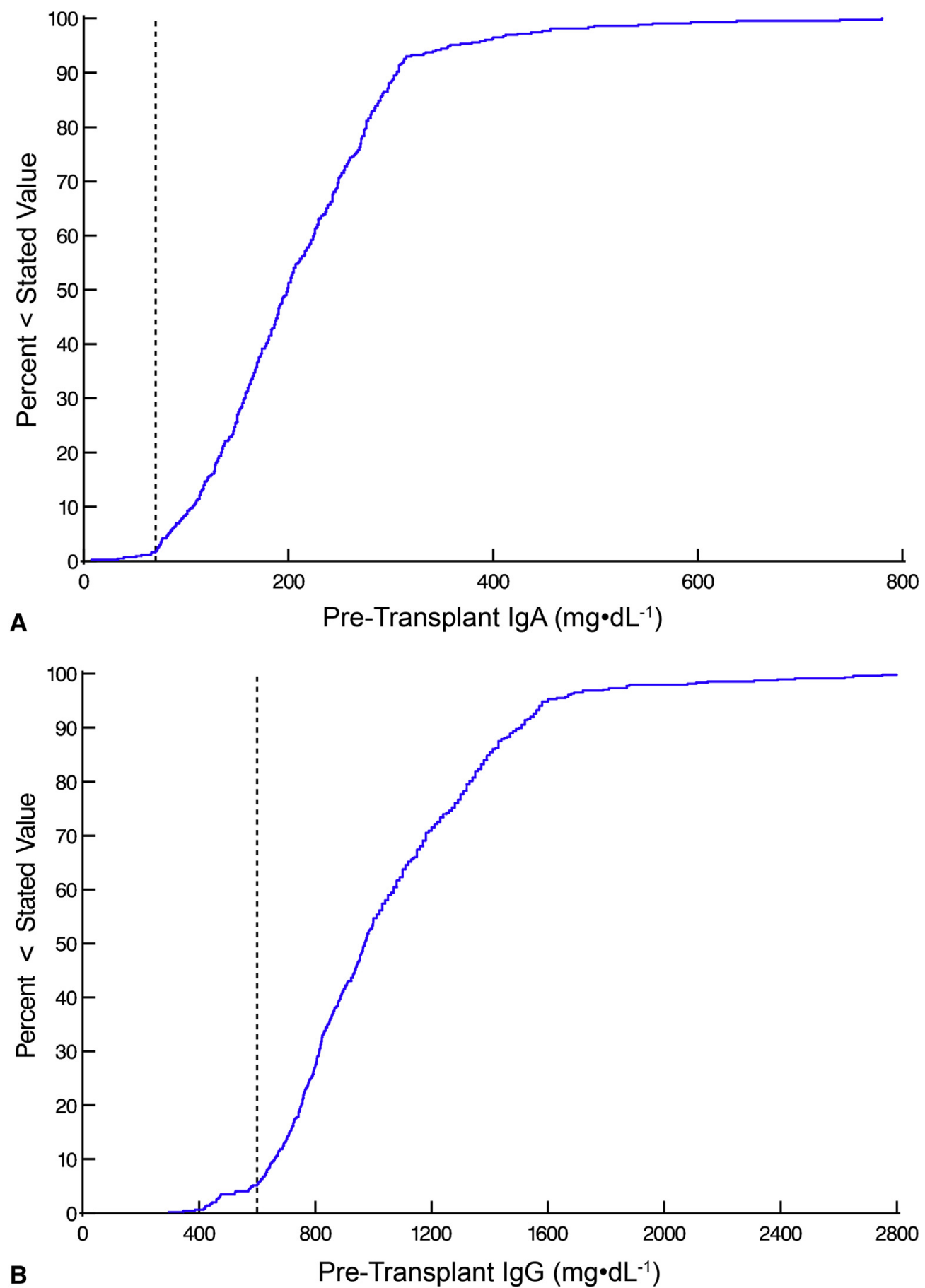

FIGURE E2. Cumulative distribution of pretransplant immunoglobulin levels. Lower limits of normal for our laboratory are shown by vertical dashed lines. A, Immunoglobulin A (IgA). B, Immunoglobulin G $(\operatorname{IgG})$. 


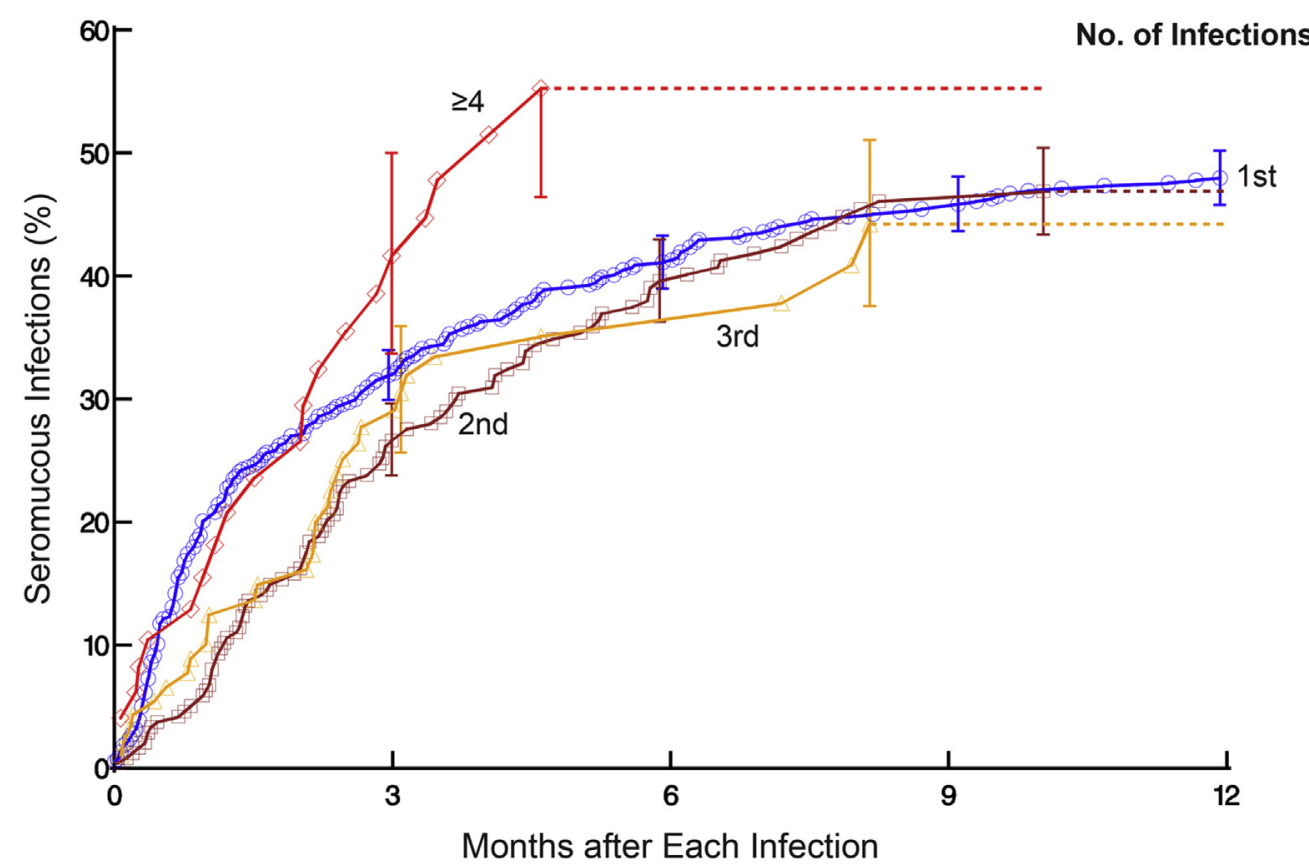

FIGURE E3. Influence of previous seromucous infections on subsequent posttransplant seromucous infections. Each symbol represents an infection and vertical bars the $68 \%$ confidence interval. Blue circles $=$ time to first infection. Brown squares = time to second infection after the first. Yellow triangles $=$ time to third infection after a second. Red diamonds $=$ time of fourth infection, or more, after a third. 


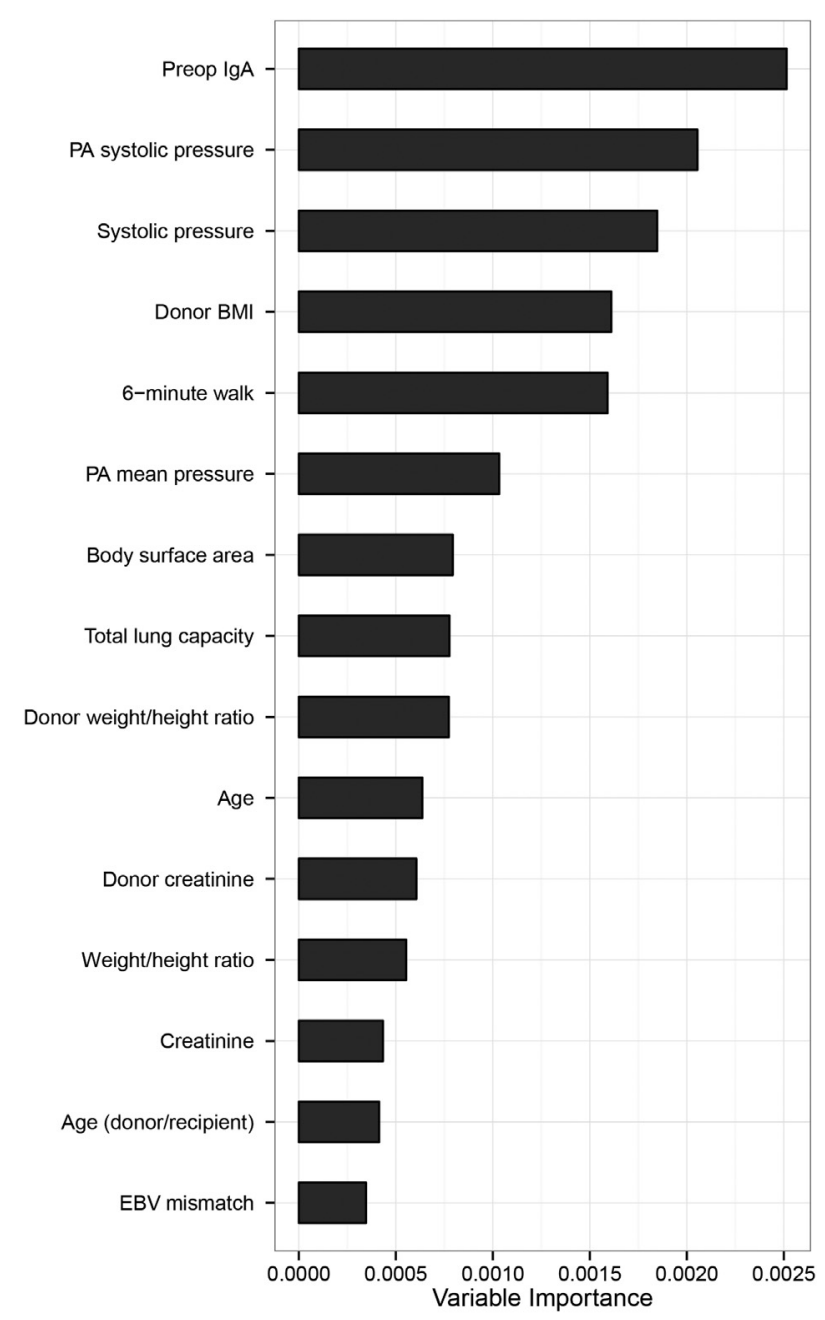

FIGURE E4. First 15 of 72 pretransplant variables with the greatest variable importance related to seromucous infections after lung transplantation. Notice that preoperative immunoglobulin A $(\operatorname{Ig} A)$ level was the foremost variable in importance in predicting seromucous infections. preop, Preoperative; $P A$, pulmonary artery; $B M I$, body mass index; $E B V$, Epstein-Barr virus. 


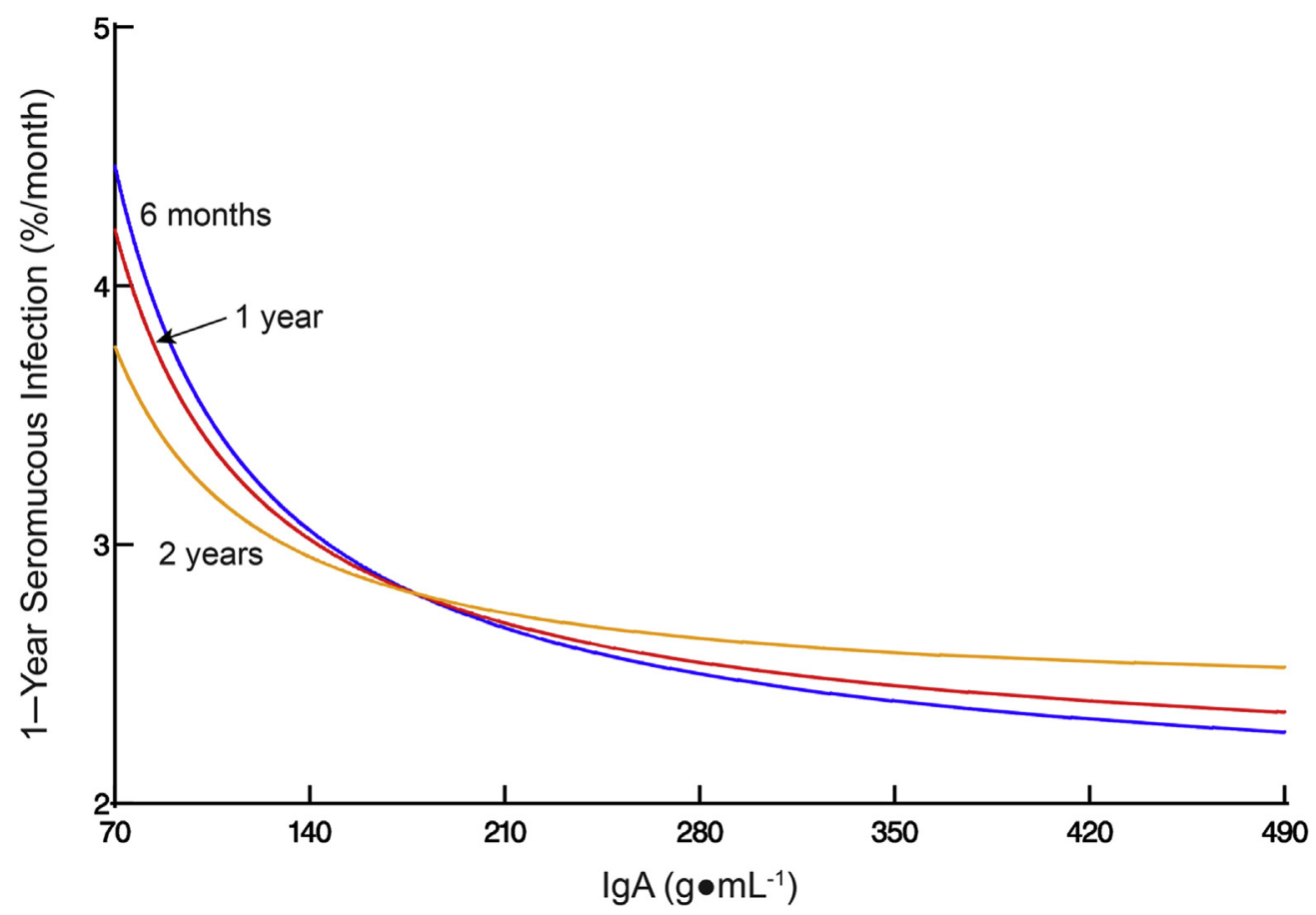

FIGURE E5. Influence of interval between IgA measurement and risk of seromucous infection within a year of transplantation. Note the small interaction effect. IgA, Immunoglobulin A.

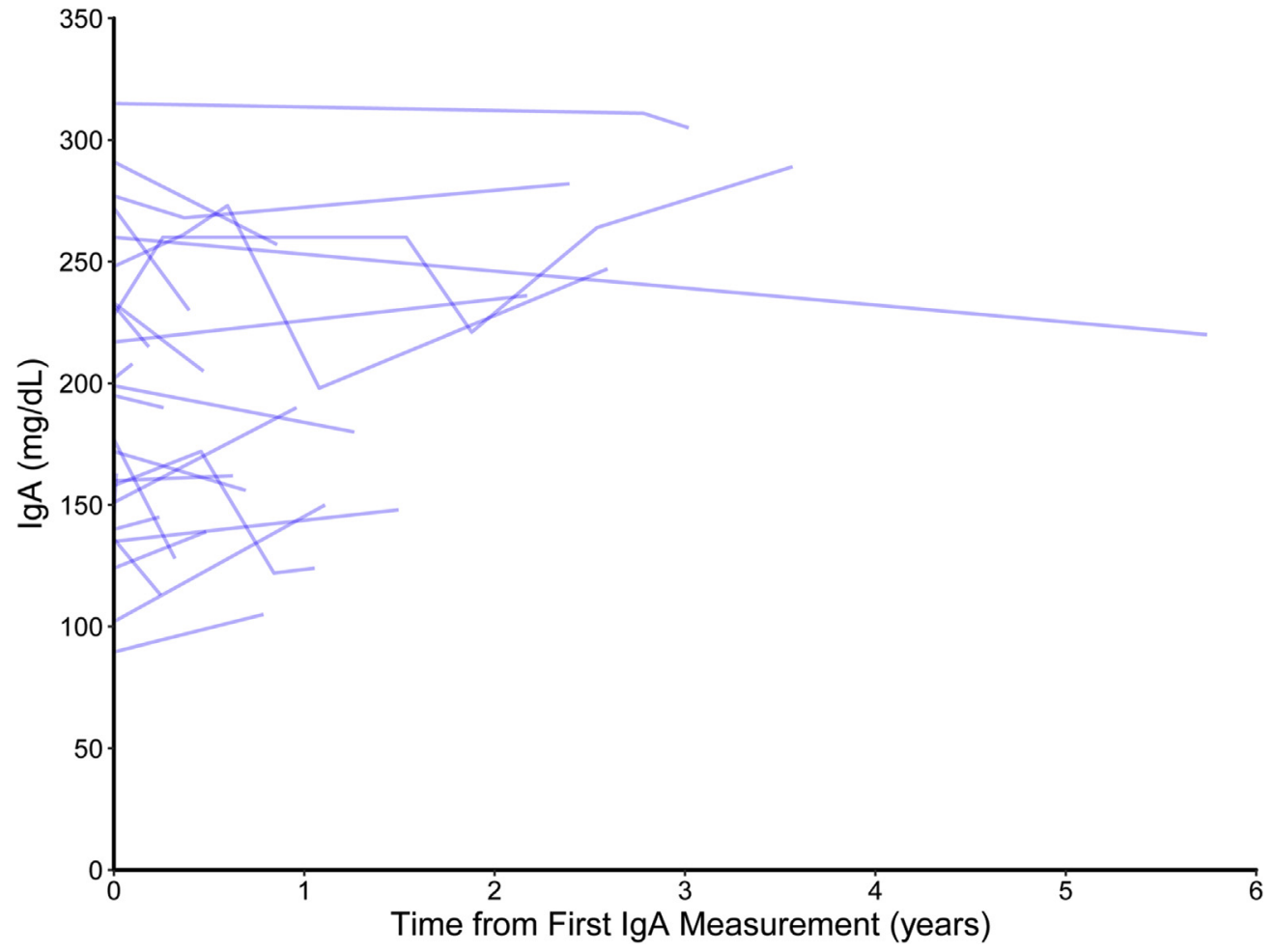

FIGURE E6. Repeated pretransplant IgA measurements. In 25 of 429 patients (5.8\%), IgA was measured more than once ( 2 measurements in 20 patients, 3 or more measurements in 5) before lung transplantation, as shown by connected points. For analysis, the value closest to transplant (last value on graph) was used. $I g A$, Immunoglobulin A. 


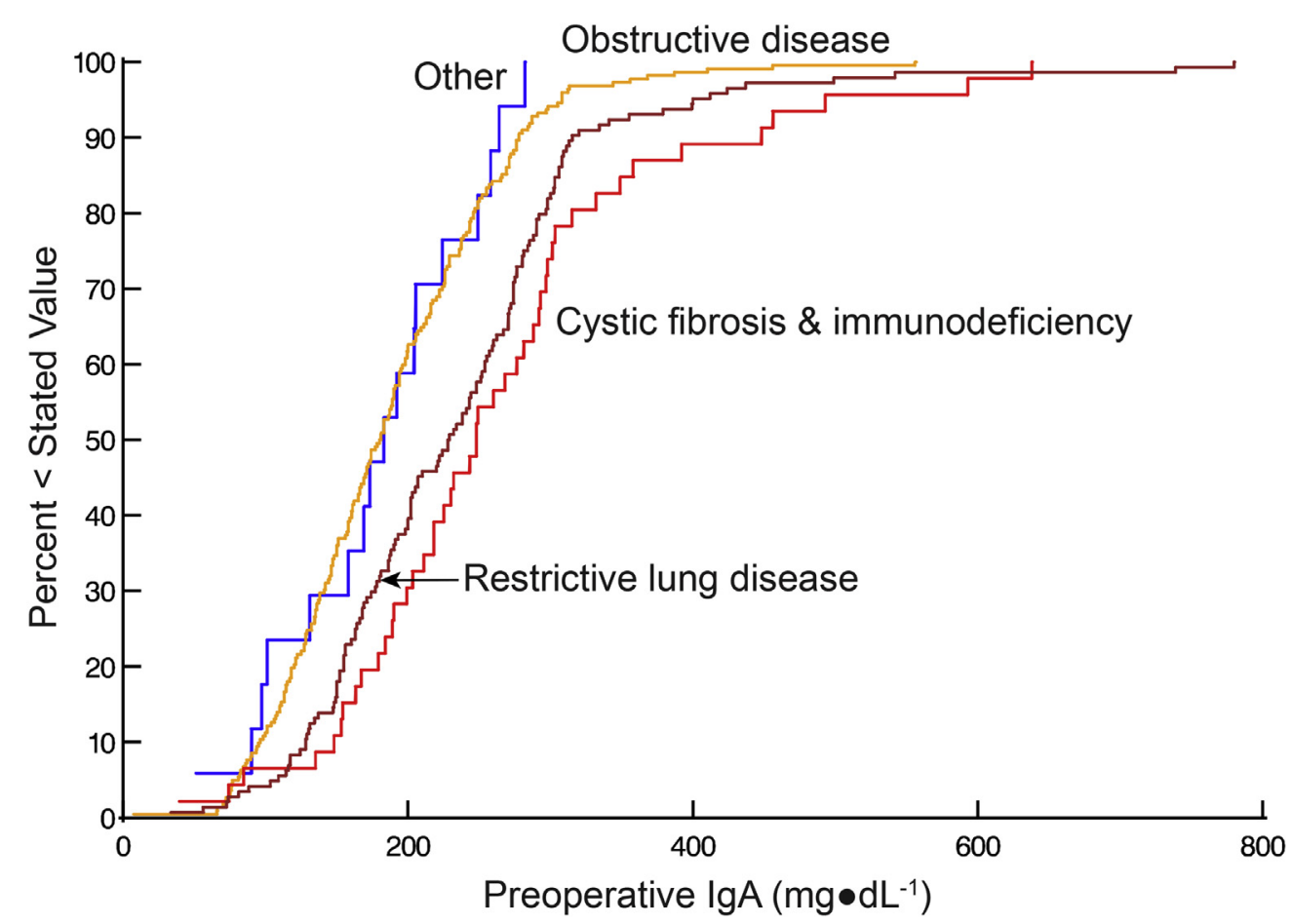

FIGURE E7. Cumulative distribution of IgA level according to primary pulmonary diagnosis. IgA, Immunoglobulin A.

TABLE E1. Type of seromucous infection overall and in immunoglobulin subgroups

\begin{tabular}{lccc}
\hline \multicolumn{1}{c}{ Type } & $\begin{array}{c}\text { Overall } \\
(\mathbf{n}=\mathbf{3 9 7})\end{array}$ & $\begin{array}{c}\text { IgA group } \\
\mathbf{n} *(\% \text { of 320 })\end{array}$ & $\begin{array}{c}\text { IgG group } \\
\mathbf{n} *(\% \text { of 349) }\end{array}$ \\
\hline Pulmonary infection & $297(75)$ & $238(74)$ & $263(75)$ \\
Urinary tract infection & $52(13)$ & $42(13)$ & $43(12)$ \\
Gastrointestinal infection & $39(9.8)$ & $32(10)$ & $36(10)$ \\
Sinusitis & $9(2.3)$ & $8(2.5)$ & $7(2.0)$ \\
\hline
\end{tabular}

IgA, Immunoglobulin A; $I g G$, immunoglobulin G. *Number of infections (some occurring more than once in a given patient) during first posttransplant year.
TABLE E2. Seromucous infectious agents by immunoglobulin subgroups

\begin{tabular}{lccc}
\hline \multicolumn{1}{c}{ Agent } & $\begin{array}{c}\text { Overall } \\
(\mathbf{n}=\mathbf{3 9 7})\end{array}$ & $\begin{array}{c}\text { IgA group } \\
\mathbf{n} *(\% \text { of 320 })\end{array}$ & $\begin{array}{c}\text { IgG group } \\
\mathbf{n} *(\% \text { of 349) }\end{array}$ \\
\hline Bacterial & $305(77)$ & $248(78)$ & $266(76)$ \\
$\quad$ Acid-fast bacilli & $1(0.25)$ & $0(0)$ & $1(0.29)$ \\
Fungal & $37(9.3)$ & $29(9.1)$ & $34(9.7)$ \\
Viral & $22(5.5)$ & $16(5.0)$ & $19(5.4)$ \\
Culture negative & $31(7.8)$ & $26(8.1)$ & $28(8.0)$ \\
Culture unavailable & $1(0.25)$ & $1(0.31)$ & $1(0.29)$ \\
\hline
\end{tabular}

$\operatorname{IgA}$, Immunoglobulin A; $\operatorname{Ig} G$, immunoglobulin G. *Number of infections (some occurring more than once in a given patient) during first posttransplant year. 
TABLE E3. Recipient factors associated with greater levels of IgA $(\mathbf{n}=\mathbf{4 2 9}) *$

\begin{tabular}{lcc}
\hline \multicolumn{1}{c}{ Factor } & Coefficient \pm SE & $\boldsymbol{P}$ \\
\hline Obstructive disease & $-0.21 \pm 0.047$ & $<.0001$ \\
$\begin{array}{l}\text { Cystic fibrosis and } \\
\text { immunodeficiency }\end{array}$ & $0.16 \pm 0.089$ & .03 \\
Older age $\dagger$ & $-0.079 \pm 0.029$ & .006 \\
Blood type other than A & $0.094 \pm 0.045$ & .04 \\
\hline
\end{tabular}

SE, Standard error. * $\log ($ preoperative $\operatorname{Ig} \mathrm{A}), \log$ arithmic transformation used as the response variable. $\dagger(50 / \text { age })^{2}$, inverse squared transformation.

TABLE E4. Risk factors for seromucosal infections in the IgG group

\begin{tabular}{lcc}
\hline \multicolumn{1}{c}{ Factor } & Coefficient \pm SE & $\boldsymbol{P}$ \\
\hline Early phase & & \\
IgG* & $-0.078 \pm 0.30$ & .8 \\
$\quad$ Diagnosis other than restrictive & $0.86 \pm 0.20$ & $<.0001$ \\
$\quad$ lung disease & & \\
Higher pretransplant FEV1 (\% of & $-0.39 \pm 0.11$ & .0005 \\
$\quad$ predicted)/FVC (\% of & & \\
$\quad$ predicted) ratio $\dagger$ & & \\
Higher donor creatinine $\ddagger$ & $0.023 \pm 0.0099$ & .02 \\
Intermediate phase & & \\
IgG $\ddagger$ & $0.21 \pm 1.2$ & .6 \\
Shorter 6-min walk & $-0.0017 \pm 0.00062$ & .008 \\
Lower FVC (\% of predicted) $\S$ & $0.52 \pm 0.25$ & .04 \\
\hline
\end{tabular}

$S E$, Standard error; $I g G$, immunoglobulin G; $F E V I$, forced expiratory volume in 1 second; $F V C$, forced vital capacity. *(IgG/1000), scaled transformation. $\dagger[1 /$ ratio FEV1 ( $\%$ of predicted)/FVC ( $\%$ of predicted)], inverse transformation. $\ddagger$ (Donor creatinine $)^{2}$, squared transformation. $\S(45 / \mathrm{FVC}$ [percent of predicted]), inverse transformation.
TABLE E5. Incremental risk factors for death in the IgG group

\begin{tabular}{lcc}
\hline \multicolumn{1}{c}{ Factor } & Coefficient \pm SE & $\boldsymbol{P}$ \\
\hline Early phase & & \\
$\quad$ IgG* & $0.023 \pm 0.21$ & .3 \\
Shorter 6-min walk & $-0.0022 \pm 0.000050$ & $<.0001$ \\
$\quad$ Higher donor creatinine & $0.47 \pm 0.11$ & $<.0001$ \\
Constant phase & & \\
IgG* & $0.23 \pm 0.21$ & .3 \\
Younger age $\dagger$ & $0.35 \pm 0.096$ & .0003 \\
Diagnosis other than cystic & $1.1 \pm 0.41$ & .007 \\
$\quad$ fibrosis and immunodeficiency & & \\
Lower donor creatinine $\ddagger$ & $-0.34 \pm 0.17$ & .05 \\
Donor cytomegalovirus IgG & $0.37 \pm 0.15$ & .01 \\
Single lung transplant & $0.51 \pm 0.16$ & .002 \\
\hline
\end{tabular}

$S E$, Standard error; $\operatorname{Ig} G$, immunoglobulin G. *(IgG/1000), scaled transformation. $\dagger(50 / \text { age })^{2}$, inverse squared transformation. $\ddagger$ Log(donor creatinine), logarithmic transformation. 